\title{
Depsipeptide Aspergillicins Revealed by Chromatin Reader Protein Deletion
}

\author{
Claudio Greco ${ }^{\dagger}$, Brandon T. Pfannenstiel ${ }^{\ddagger}$, James C. Liu ${ }^{\dagger}$, Nancy P. Keller ${ }^{\star}, \dagger, \S$ \\ tDepartment of Medical Microbiology and Immunology, University of Wisconsin-Madison, \\ Madison, Wisconsin, United States \\ ‡Department of Genetics, University of Wisconsin-Madison, Madison, Wisconsin, United States \\ §Department of Bacteriology, University of Wisconsin—Madison, Madison, Wisconsin, United \\ States
}

\section{Abstract}

Expression of biosynthetic gene clusters (BGCs) in filamentous fungi is highly regulated by epigenetic remodeling of chromatin structure. Two classes of histone modifying proteins, writers (which place modifications on histone tails) and erasers (which remove the modifications), have been used extensively to activate cryptic BGCs in fungi. Here, for the first time, we present activation of a cryptic BGC by a third category of histone modifying proteins, reader proteins that recognize histone tail modifications and commonly mediate writer and eraser activity. Loss of the reader SntB $(\Delta s n t B)$ resulted in the synthesis of two cryptic cyclic hexa-depsipeptides, aspergillicin A and aspergillicin F, in the fungus Aspergillus flavus. Liquid chromatography, high resolution mass spectrometry, and NMR analysis coupled with bioinformatic analysis and gene deletion experiments revealed that a six adenylation (A) domain nonribosomal peptide synthetase (NRPS, called AgiA) and $O$-methyltransferase (AgiB) were required for metabolite formation. A proposed biosynthetic scheme illustrates the requirement for unusual NRPS domains, such as a starting condensation domain and a thiolesterase domain proposed to cyclize the depsipeptides. This latter activity has only been found in bacterial but not fungal NRPS. The agi BGC-unique to A. flavus and some closely related species (e.g., A. oryzae, A. arachidicola)—is located next to a conserved Aspergillus siderophore BGC syntenic to other fungi.

\section{Graphical abstract}

\footnotetext{
*Corresponding Author npkeller@wisc.edu. Author Contributions

C.G. performed and executed the experiments. B.T.P. assisted with experimental design and editing the manuscript. J.C.L. supported the confirmation of the mutants. N.P.K. provided materials and equipment. C.G. and N.P.K. conceived and designed the study and wrote the manuscript. ASSOCIATED CONTENT

Supporting Information

The Supporting Information is available free of charge on the ACS Publications website at DOI: 10.1021/acschem-bio.9b00161.

Experimental procedures, supporting figures, supporting tables, and compound characterization (PDF)

The authors declare no competing financial interest.
} 


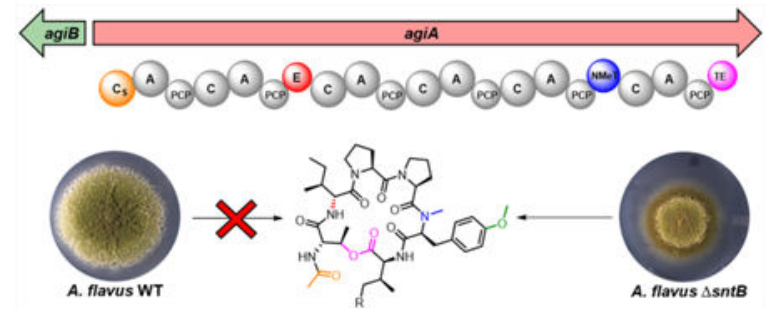

Fungi are a great source of bioactive molecules, and bioinformatic studies have revealed that their genomes encode many biosynthetic gene clusters (BGCs) which could potentially be involved in the synthesis of pharmaceutically relevant secondary metabolites. ${ }^{1}$ However, most fungal BGCs are not expressed in laboratory growth conditions and require activation through synthetic means. Epigenetic strategies-primarily by deleting or overexpressing histone methyltransferases, demethylases, acetylases, and deacetylases—-have been successfully utilized to "awaken" cryptic BGCs., ${ }^{2,3}$ These histone modifying enzymes are classified as "writers" (methyltransferases, acetyltransferases) or "erasers" (deacetylases, demethylases) by virtue of their placement or removal of histone tail modifications.

A third category of histone modifying proteins, "reader" proteins, are required to identify histone modifications and guide writer and eraser proteins to the correct location on the histone tail. ${ }^{4}$ Only recently has a reader protein been shown to be involved in secondary metabolism in fungi. ${ }^{4-6}$ Specifically, a forward genetic screen resulted in the identification of the reader protein, SntB, in global regulation of histone modifications (H3K9K14ac and H3K4me3) and BGC activation and repression in Aspergillus nidulans and A. flavus, ${ }^{4}$ Although up to $50 \%$ of $A$ nidulans BGCs have been assigned to the product, only 14 secondary metabolites have been assigned to the predicted ca. $70 \mathrm{BGCs}$ of $A$ flavus. ${ }^{4}$ Here, we demonstrate the utility of reader proteins in mining the fungal secondary metabolome through activation of the cryptic $A$. flavus aspergillicin ( $\left.a g_{i}\right)$ BGC. Synthesis of these metabolites required a nonribosomal peptide synthetase (NRPS) and $O$-methyltransferase. Analysis of the NRPS architecture revealed a starting condensation domain putatively involved in capping of the $\mathrm{N}$-terminus of tyrosine and a final thiolesterase domain, proposed to cyclize the depsipeptides, which, to our knowledge, is the first example in fungal NRPS. ${ }^{8}$ Phylogenetic analysis places this BGC-unique to Aspergillus species closely related to $A$. flavus - next to a syntenic region in the taxa Eurotiales containing the extracellular siderophore BGC.

\section{RESULTS AND DISCUSSION}

Previously, we had identified SntB as a reader protein required for the biosynthesis of the carcinogen aflatoxin B1. In A. flavus, SntB regulates several secondary metabolites; for example, aflatrem, aflavarin, and asparasone A were positively regulated. In contrast, ditryptophenaline and leporin B were negatively regulated, and the $\Delta s n t B$ strain could produce higher titers of them in standard growth conditions, glucose minimal media (GMM) and potato dextrose agar (PDA) at $30{ }^{\circ} \mathrm{C}$ for 14 days, being up-regulated in the mutant. ${ }^{4} \mathrm{We}$ therefore thought it possible that additional cryptic compounds would be produced by $\Delta s n t B$. The $\Delta s n t B A$. flavus strain was grown on several media, and the crude extract was 
further screened for the production of novel metabolites using high-performance liquid chromatography (HPLC) with a photodiode array detector and ultraperformance liquid chromatography (UPLC) coupled with high-resolution mass spectrometry (HRMS). The mutant strain presented a distinct phenotype and two metabolites, $\mathbf{1}$ and $\mathbf{2}$, only detected in trace amounts in the wild-type (WT) strain. $\mathbf{1}$ and $\mathbf{2}$ were produced in good titers in the $\Delta s n t B$ strain when it was grown in solid or liquid potato dextrose media (Figure 1A). HRMS analysis predicted the molecular formulas $\mathrm{C}_{38} \mathrm{H}_{56} \mathrm{~N}_{6} \mathrm{O}_{9}\left(741.4171[\mathrm{M}+\mathrm{H}]^{+}\right)$for $\mathbf{1}$ and $\mathrm{C}_{39} \mathrm{H}_{58} \mathrm{~N}_{6} \mathrm{O}_{9}\left(754.4324[\mathrm{M}+\mathrm{H}]^{+}\right)$for 2 , consistent with peptide products.

The molecular formula of compound $\mathbf{1}$ matched the molecular formula of the previously reported aspergillicin A, and NMR analysis (Figure S19) was in agreement with the literature. ${ }^{9,10}$ The molecular formula of compound $\mathbf{2}$ was consistent with the two isomers, aspergillicin $\mathrm{E}$ and $\mathrm{F}$. Kikuchi et al. confirmed by total synthesis that aspergillicin E contains L-allo-isoleucine ( $a-\mathrm{H} 4.68 \mathrm{ppm} ; J=9.2,4.8 \mathrm{~Hz}$ ), and aspergillicin $\mathrm{F}$ has instead an Lisoleucine ( $a-\mathrm{H} 4.52 \mathrm{ppm} ; J=8.8,5.6) .{ }^{9}$ NMR data of compound 2 were in agreement with the structure of aspergillicin F, in particular, the L-isoleucine moiety ( $a-\mathrm{H} 4.55 ; J=8.6,5.6$; Table S4). Together with aspergillicin A 1, aspergillicins B-E 3-6 were isolated from $A$. carneus, ${ }^{10}$ while aspergillicin $\mathrm{F} 2$ was recently isolated from Aspergillus sp. f19703 (Figure 1B). ${ }^{9}$ Aspergillicin $\mathrm{F}$ was reported to have activity as an innate immune suppressor. ${ }^{9}$ Although A. flavus has been studied for the production of secondary metabolites, it was never reported to produce any aspergillicins.

To discern what BGC could be producing aspergillicins, we used the recently improved BGC software fungiSMASH (v4.1.0) ${ }^{11}$ to reanalyze the genome of $A$ flavus NRRL3357, the strain used in our study. We identified 70 putative BGCs; to these, the ustiloxin ${ }^{12}$ and kojic acid ${ }^{13}$ BGCs need to be added as they are not recognized by this software. Only 14 of these 72 BGCs have been linked to a product. ${ }^{4}$ Aspergillicins are likely to be synthesized by an NRPS, and bioinformatic analysis identified 18 putative canonical NRPS encoding genes (Table 1). Of these, only two have been linked to peptide products, ditryptophenaline ${ }^{14}$ and imizoquin. ${ }^{15}$ In addition, four more NRPSs could be predicted to produce specific products, based on their high homology to characterized genes in other species (Table 1, yellow rows).

As aspergillicins are derived from six amino acids, this suggests that they may be synthesized by an NRPS encoding six adenylation (A) domains, and only one NRPS (AFLA_010580) met this architecture. The NRPS, termed AgiA (aspergillicin), displays a starting condensation domain $\left(\mathrm{C}_{\mathrm{s}}\right)$, which could load acetyl CoA and add it to the $N$ terminus of threonine. This is similar to PKS/NRPS hybrids, where the first module of the NRPS is a $\mathrm{C}_{\mathrm{s}}$-domain, which loads the acyl chain synthesized by the PKS moiety (e.g., tenellin). ${ }^{21}$ Another close example is the biosynthesis of the bacterial lipopeptide holrhizin A, where the NRPS contains a $\mathrm{C}_{\mathrm{S}}$ domain involved in loading the acyl moiety to the $\mathrm{N}$ terminus of the first amino acid. ${ }^{22}$ The NRPS also contains more common domains including an epimerase (E) domain on module 2, consistent with the formation of the Disoleucine moiety. Module 5 contains an $N$-methyl transferase (NMeT), which could catalyze the $N$-methylation of phenylalanine/tyrosine. 
One unique feature of AgiA is the proposed activity of the thiolesterase (TE) domain, which could cyclize the peptide using the hydroxy group from threonine to form the cyclic depsipeptide (Figure 2A). A TE domain involved in the cyclization of peptides, while common in bacteria, has not been reported for fungal cyclic peptides. ${ }^{8}$ Usually in fungi this final cyclization is performed by a terminal condensation $\left(\mathrm{C}_{\mathrm{T}}\right)$ domain. TE domains are found in fungal NRPS, but they are associated with the hydrolysis of linear peptides, like L$a$-aminoadipate-L-Cys-D-Val (ACV) synthetase or imizoquin synthetase (ImqB; Figure S9). 8,15

Further bioinformatic analysis revealed that the NRPS gene (agiA) was flanked on one side by two small (91 aa each) hypothetical proteins with no predicted function (AFLA_010570 and AFLA_010560) and an $O$-methyl transferase (agiB, AFLA_010550), which could be involved in the methylation of tyrosine. AgiB has homology with known $O$-methyl transferases involved in the $O$-methylation of tyrosine, like AsqN (54\%) for the biosynthesis of aspoquinolones and $4^{\prime}$-methoxyviridicatin $\mathbf{1 0}^{23}$ and XanE (35\%) for the biosynthesis of xanthocillin. ${ }^{24}$ Interestingly, the other side was flanked by four genes homologous to the $A$. fumigatus siderophore biosynthetic genes ( $s i d D$, $s i d F$, $s i d H$, and $s i d J$ ), which are required for production of the extracellular siderophores fusarinine $\mathrm{C}(\mathrm{FC}) 7$ and $\mathrm{N}, \mathrm{N}^{\prime}, \mathrm{N}^{\prime \prime}-$ triacetylfusarinine C (TAFC) 8, but they have not been investigated in A. flavus (Figure 2B). $16,25,26$ Some of these genes could potentially be involved in aspergillicin biosynthesis, in particular sidJ and sidF. sidJ encodes for esterase protein, reported in A. fumigatus to degrade FC 7 by hydrolyzation, and could potentially hydrolyze aspergillicins as well. ${ }^{27}$ $\mathrm{SidF}$ is an $\mathrm{N}$-acyl transferase, which is involved in the biosynthesis of $\mathbf{7}$ and $\mathbf{8}$ in $A$. fumigatus, ${ }^{16}$ and could catalyze the acetylation of threonine in the aspergillicins. This genomic region was then compared to different fungi using BLAST, ${ }^{28}$ Artemis Comparison Tool (ACT; Figure S3-6), ${ }^{29}$ and MultiGeneBlast. ${ }^{30}$ It was found that while the siderophore region is fairly conserved across different fungi (Figure S7), AgiA only displayed significant similarity with NRPS encoded by the closely related Aspergillus spp., e.g., A. oryzae (99\%) and $A$. arachidicola (95\%). ${ }^{31}$ Interestingly, $A$. fumigatus encodes, in the same position, a much smaller bimodular NRPS, SidE, which was identified to be the only gene involved in the biosynthesis of fumarylalanine 9 but was not involved in siderophore biosynthesis despite the name SidE. ${ }^{32}$

In order to confirm the role of agiA and other flanking genes in the biosynthesis of aspergillicins, several mutants were generated using $A$. flavus $\Delta s n t B$ as the parental control strain. The $\Delta \Delta$ sntB/agiA double mutant strain was generated and grown on PDA for 2 weeks at $30{ }^{\circ} \mathrm{C}$ and the metabolites extracted and analyzed by UPLC-HRMS (Figure 3 ). This mutant was not able to produce aspergillicin $\mathrm{A} \mathbf{I}$ and $\mathrm{F} \mathbf{2}$, providing evidence that AgiA is involved in their biosynthesis. The $O$-methyl transferase (agiB) was also investigated by a gene deletion experiment. The $\Delta \Delta s n t B / a g i B$ double mutant strain was grown, extracted, and analyzed by UPLC-HRMS. In this case as well, aspergillicin A $\mathbf{l}$ and F 2 were not produced (Figure 3). But instead, two novel metabolites with very similar retention times were detected, and their molecular formulas were predicted to be $\mathrm{C}_{37} \mathrm{H}_{54} \mathrm{~N}_{6} \mathrm{O}_{8}(711.4072[\mathrm{M}+$ $\mathrm{H}]^{+}$) and $\mathrm{C}_{38} \mathrm{H}_{56} \mathrm{~N}_{6} \mathrm{O}_{8}\left(725.4232[\mathrm{M}+\mathrm{H}]^{+}\right)$, consistent with the loss of a methoxy group for each metabolite. Isolation of these compounds using preparative HPLC and analysis by 
NMR showed that the methoxy signal from 1 and $2\left(\delta_{\mathrm{H}} 3.78 \mathrm{ppm}\right)$ was not present, but instead a new aromatic signal for each new compound was observed $\left(\delta_{\mathrm{H}} 7.25\right.$ and $7.27 \mathrm{ppm}$, respectively; Table S5). The metabolites were confirmed to be aspergillicin $\mathrm{C} \mathbf{4}$ and a novel aspergillicin, with almost the same structure as aspergillicin E, but with a phenylalanine instead of a tyrosine moiety. This was termed aspergillicin G $\mathbf{1 1}$.

These results suggested some flexibility in amino acid recognition by the $\mathrm{A}_{5}$-module dependent on the presence of the $O$-methyl transferase AgiB. To examine this hypothesis, the $\Delta \Delta s n t B / a g i B$ strain was grown under producing conditions and supplemented with $O$ Me-L-tyrosine over 3 days (days 5, 6, and 7). The culture was extracted, and UPLC-HRMS analysis showed that the production of aspergillicin A $\mathbf{1}$ and aspergillicin F $\mathbf{2}$ was restored (Figure 3). Masses consistent with the aspergillicin derivatives containing tyrosine were not detected in the $\Delta \Delta$ sntB/agiB. This suggests that AgiB can methylate tyrosine, and that the $\mathrm{A}_{5}$-domain preferentially incorporates $O$-Me-L-tyrosine, but it can also accept Lphenylalanine. A similar situation was reported for the biosynthesis of $4^{\prime}$-methoxyviridicatin 10; in this case it was shown by in vitro studies that the NRPS AsqK could accept Lphenylamine or $O$-Me-L-tyrosine, but the latter was incorporated into the final product preferentially by 10 -fold. ${ }^{23}$

Although AgiA and AgiB should be enough to catalyze the biosynthesis of aspergillicin A and $\mathrm{F}$, we investigated the involvement of SidJ and SidF by gene deletion experiments considering our rationale above. sidJ encodes an esterase protein, and in $A$. fumigatus the homologous protein (protein identity $71 \%$ ) was shown to be involved in the degradation of fusarinine C. Disruption of this gene in $A$. fumigatus resulted in a very sick phenotype under iron starvation conditions. ${ }^{27}$ In order to assess if this enzyme could also impact the production of aspergillicins, we created the $\Delta \Delta s n t B / s i d J$ strain. UPLC-HRMS analysis showed no changes in the production of 1 and 2 (Figure 3). sidF encodes an $N$ acyltransferase, and it is homologous to $s i d F$ in $A$. fumigatus (protein identity $82 \%$ ). This gene was reported to be involved in one of the final steps for the biosynthesis of FC 7 and TAFC 8. ${ }^{16,33}$ In order to exclude that this gene is not acetylating aspergillicins, the $\Delta \Delta s n t B /$ $s i d F$ strain was prepared and grown under aspergillicin producing conditions. UPLC-HRMS analysis of the extract showed that aspergillicin A $\mathbf{1}$ and $\mathrm{F} \mathbf{2}$ were produced (Figure 3). These two experiments confirmed that sidJ and sidF are not involved in the biosynthesis of aspergillicins. Together, these gene deletion experiments validated that the biosynthesis of aspergillicin A and aspergillicin $\mathrm{F}$ is catalyzed solely by the $O$-methyl transferase AgiB and the NRPS AgiA (Figure 2A). To further validate if the genes were differentially expressed, reverse transcriptase quantitative PCR (RT-qPCR) experiments were done for the WT and the $\Delta$ snt $B$ strains. Interestingly, at day 2 and day 3, the expression of the agi $A$ and agiB genes was higher by 2 to $4 \log$ folds in the $\Delta s n t B$ strains (Figure S12).

Since the aspergillicin BGC is located in close proximity to the siderophore genes, we wanted to determine the fitness of these mutants under different iron concentrations. Each strain was serially passaged three times on glucose minimal media lacking iron, in order to deplete intracellular iron. Then, the strains were plated on plates containing no iron, a normal growth media level of $\mathrm{FeSO}_{4}(5 \mu \mathrm{M})$, a high level of $\mathrm{FeSO}_{4}(1 \mathrm{mM})$, and a very high level of $\mathrm{FeSO}_{4}(10 \mathrm{mM}$; Figure S13). There was a mild growth defect of the $\Delta s n t B$ strain in 
comparison to the WT strain at all the different iron concentrations, in agreement with a previous report of this mutant. ${ }^{4}$ When comparing the double mutants to $\Delta s n t B$ control, the $\Delta \Delta s n t B / s i d J$ strain was the only strain to show an observable growth defect on zero $\mathrm{FeSO}_{4}$ treatment. However, this strain was severely crippled on high and very high concentrations of $\mathrm{FeSO}_{4}$, as reported for a loss of $s i d J$ in $A$. fumigatus under iron starvation. ${ }^{27,33}$ Interestingly, a growth defect was also observed for the $\Delta \Delta s n t B / a g i A$ strain, especially under a very high $\mathrm{FeSO}_{4}$ concentration. This could implicate that the aspergillicins may also be involved in the regulation of iron, a future interest of our lab.

\section{CONCLUSION}

In conclusion, we have demonstrated that the epigenetic reader SntB can direct the production of uncharacterized secondary metabolites. The deletion of this gene allowed the isolation of two cyclic depsipeptides, aspergillicin A $\mathbf{1}$ and aspergillicin F 2, which were not isolated from A. flavus before. Aspergillicin $\mathrm{F}$ is of particular interest because it was previously reported to have innate immune-modulating activity. ${ }^{9}$ Bioinformatic analysis and gene disruption experiments identified the biosynthetic genes to be the hexamodular NRPS AgiA and the $O$-methyl transferase AgiB. AgiA contains a $\mathrm{C}_{\mathrm{s}}$ domain that we propose is loading acetyl $\mathrm{CoA}$ for $\mathrm{N}$-acetylation of threonine. AgiA also contains a final TE domain putatively involved in product cyclization, an activity which has not been reported for fungal NRPS. The $\mathrm{A}_{5}$-domain loads preferentially $O$-Me-L-tyrosine, which is synthesized by the $O$ methyl transferase AgiB. Deletion of agiB resulted in the biosynthesis of aspergillicin $\mathrm{C} 4$ and a novel derivative called aspergillicin G 11. RT-qPCR analysis determined that in the $\Delta s n t B$ strain the expression of agi $A$ and agiB was higher. In addition, comparative analysis identified these cryptic BGCs to be located next to a conserved siderophore BGC characterized in $A$. fumigatus and $A$. nidulans that synthesizes extracellular siderophores FC 7 and TAFC 8. ${ }^{34}$ The two agi $A$ adjacent siderophore genes ( $s i d J$ and sidF) were disrupted and found not to be involved in aspergillicin biosynthesis. The strains were tested for susceptibility to different iron concentrations. As expected, the mutant $\Delta$ sid $J$ showed a sick phenotype, in particular under high iron conditions, in agreement with the experiments reported for A. fumigatus. ${ }^{27}$ Interestingly, the NRPS AgiA mutant also showed a fairly significant growth defect at a high concentration of iron, possibly indicating that aspergillicins may contribute to iron homeostasis in A. flavus.

Overall, our findings have uncovered another epigenetic tool to mine the fungal genome. Although many studies have utilized histone writers and erasers to uncover cryptic secondary metabolites, ${ }^{3}$ our study highlights the potential of using a reader protein in such a role. We anticipate that further studies of reader domain proteins and their interactive protein complexes will continue to elucidate the hidden treasures of the fungal metabolome.

\section{Supplementary Material}

Refer to Web version on PubMed Central for supplementary material. 


\section{ACKNOWLEDGMENTS}

The authors would like to thank T. Bugni and F. Zhang for assistance at the beginning of the project. We would also like to thank the UW-Madison NMR facility for training, in particular, H. Hofstetter; the Bruker Avance-600 was supported by NIH S10 OK012245 and the Bruker Avance III 500 spectrometer by Bender Fund. Funding was provided in part by NIH R01GM112739-01 to N.P.K. B.T.P. was supported by the Predoctoral Training Program in Genetics, funded by the NIH 5T32 GM007133-40.

\section{REFERENCES}

(1). Keller NP (2019) Fungal secondary metabolism: regulation, function and drug discovery. Nat. Rev. Microbiol. 17, 167-180. [PubMed: 30531948]

(2). Strauss J, and Reyes-Dominguez Y (2011) Regulation of secondary metabolism by chromatin structure and epigenetic codes. Fungal Genet. Biol. 48, 62-69. [PubMed: 20659575]

(3). Pfannenstiel BT, and Keller NP (2019) On top of biosynthetic gene clusters: How epigenetic machinery influences secondary metabolism in fungi. Biotechnol. Adv., DOI: 10.1016/ j.biotechadv.2019.02.001.

(4). Pfannenstiel BT, Greco C, Sukowaty AT, and Keller NP (2018) The epigenetic reader SntB regulates secondary metabolism, development and global histone modifications in Aspergillus flavus. Fungal Genet. Biol. 120, 9-18. [PubMed: 30130575]

(5). Reyes-Dominguez Y, Boedi S, Sulyok M, Wiesenberger G, Stoppacher N, Krska R, and Strauss J (2012) Heterochromatin influences the secondary metabolite profile in the plant pathogen Fusarium graminearum. Fungal Genet. Biol. 49, 39-47. [PubMed: 22100541]

(6). Shinohara Y, Kawatani M, Futamura Y, Osada H, and Koyama Y (2016) An overproduction of astellolides induced by genetic disruption of chromatin-remodeling factors in Aspergillus oryzae. J. Antibiot. 69, 4-8. [PubMed: 26126743]

(7). Pfannenstiel B, Zhao X, Wortman J, Wiemann P, Throckmorton K, Spraker JE, Soukup AA, Luo X, Lindner DL, Lim Y, Knox BP, Haas B, Fischer GJ, Choera T, Butchko RAE, Bok J, Affeldt KJ, Keller NP, and Palmer JM (2017) Revitalization of a Forward Genetic Screen Identifies Three New Regulators. mBio 8, 1-15.

(8). Gao X, Haynes SW, Ames BD, Wang P, Vien LP, Walsh CT, and Tang Y (2012) Cyclization of fungal nonribosomal peptides by a terminal condensation-like domain. Nat. Chem. Biol. 8, 82330. [PubMed: 22902615]

(9). Kikuchi H, Hoshikawa T, Fujimura S, Sakata N, Kurata S, Katou Y, and Oshima Y (2015) Isolation of a Cyclic Depsipetide, Aspergillicin F, and Synthesis of Aspergillicins with Innate Immune-Modulating Activity. J. Nat. Prod. 78, 1949-1956. [PubMed: 26273902]

(10). Capon RJ, Skene C, Stewart M, Ford J, O’Hair RAJ, Williams L, Lacey E, Gill JH, Heiland K, and Friedel T (2003) Aspergillicins A-E: Five novel depsipeptides from the marine-derived fungus Aspergillus carneus. Org. Biomol. Chem. 1, 1856-1862. [PubMed: 12945765]

(11). Blin K, Wolf T, Chevrette MG, Lu X, Schwalen CJ, Kautsar SA, Suarez Duran HG, de los Santos ELC, Kim HU, Nave M, Dickschat JS, Mitchell DA, Shelest E, Breitling R, Takano E, Lee SY, Weber T, and Medema MH (2017) antiSMASH 4.0-improvements in chemistry prediction and gene cluster boundary identification. Nucleic Acids Res. 45, W36-W41. [PubMed: 28460038]

(12). Ye Y, Minami A, Igarashi Y, Izumikawa M, Umemura M, Nagano N, Machida M, Kawahara T, Shin-ya K, Gomi K, and Oikawa H (2016) Unveiling the Biosynthetic Pathway of the Ribosomally Synthesized and Post-translationally Modified Peptide Ustiloxin B in Filamentous Fungi. Angew. Chem., Int. Ed. 55, 8072-8075.

(13). Ammar HAM, Srour AY, Ezzat SM, and Hoseny AM (2017) Identification and characterization of genes involved in kojic acid biosynthesis in Aspergillus flavus. Ann. Microbiol. 67, 691-702.

(14). Saruwatari T, Yagishita F, Mino T, Noguchi H, Hotta K, and Watanabe K (2014) Cytochrome P450 as Dimerization Catalyst in Diketopiperazine Alkaloid Biosynthesis. ChemBioChem 15, 656-659. [PubMed: 24677498]

(15). Khalid S, Baccile JA, Spraker JE, Tannous J, Imran M, Schroeder FC, and Keller NP (2018) NRPS-Derived Isoquino-lines and Lipopetides Mediate Antagonism between Plant Pathogenic Fungi and Bacteria. ACS Chem. Biol. 13, 171-179. [PubMed: 29182847] 
(16). Schrettl M, Bignell E, Kragl C, Sabiha Y, Loss O, Eisendle M, Wallner A, Arst HN, Haynes K, and Haas H (2007) Distinct Roles for Intra-and Extracellular Siderophores during Aspergillus fumigatus Infection. PLoS Pathog. 3, No. e128.

(17). Chankhamjon P, Boettger-Schmidt D, Scherlach K, Urbansky B, Lackner G, Kalb D, Dahse HM, Hoffmeister D, and Hertweck C (2014) Biosynthesis of the Halogenated Mycotoxin Aspirochlorine in Koji Mold Involves a Cryptic Amino Acid Conversion. Angew. Chem. Int. Ed. 53, 13409-13413.

(18). O’Hanlon KA, Gallagher L, Schrettl M, Jöchl C, Kavanagh K, Larsen TO, and Doyle S (2012) Nonribosomal peptide synthetase genes pesL and pes1 are essential for Fumigaclavine $\mathrm{C}$ production in Aspergillus fumigatus. Appl. Environ. Microbiol. 78, 3166-76. [PubMed: 22344643]

(19). Reeves EP, Reiber K, Neville C, Scheibner O, Kavanagh K, and Doyle S (2006) A nonribosomal peptide synthetase (Pes1) confers protection against oxidative stress in Aspergillus fumigatus. FEBS J. 273, 3038-3053. [PubMed: 16759234]

(20). Georgianna DR, Fedorova ND, Burroughs JL, Dolezal AL, Bok JW, Horowitz-Brown S, Woloshuk CP, Yu J, Keller NP, and Payne GA (2010) Beyond aflatoxin: four distinct expression patterns and functional roles associated with Aspergillus flavus secondary metabolism gene clusters. Mol. Plant Pathol. 11, 213-26. [PubMed: 20447271]

(21). Halo LM, Marshall JW, Yakasai AA, Song Z, Butts CP, Crump MP, Heneghan M, Bailey AM, Simpson TJ, Lazarus CM, and Cox RJ (2008) Authentic Heterologous Expression of the Tenellin Iterative Polyketide Synthase Non-ribosomal Peptide Synthetase Requires Coexpression with an Enoyl Reductase. ChemBioChem 9, 585-594. [PubMed: 18266306]

(22). Niehs SP, Scherlach K, and Hertweck C (2018) Genomics-driven discovery of a linear lipopeptide promoting host colonization by endofungal bacteria. Org. Biomol. Chem. 16, 83458352. [PubMed: 30209475]

(23). Ishikawa N, Tanaka H, Koyama F, Noguchi H, Wang CCC, Hotta K, and Watanabe K (2014) Non-Heme Dioxygenase Catalyzes Atypical Oxidations of 6,7-Bicyclic Systems To Form the 6,6-Quinolone Core of Viridicatin-Type Fungal Alkaloids. Angew. Chem., Int. Ed. 53, 1288012884.

(24). Lim FY, Won TH, Raffa N, Baccile JA, Wisecaver J, Rokas A, Schroeder FC, and Keller NP (2018) Fungal Isocyanide Synthases and Xanthocillin Biosynthesis in Aspergillus fumigatus. mBio 9, e00785-18.

(25). Cleveland TE, Yu J, Fedorova N, Bhatnagar D, Payne GA, Nierman WC, and Bennett JW (2009) Potential of Aspergillus flavus genomics for applications in biotechnology. Trends Biotechnol 27, 151-157. [PubMed: 19195728]

(26). Reiber K, Reeves EP, Neville CM, Winkler R, Gebhardt P, Kavanagh K, and Doyle S (2005) The expression of selected non-ribosomal peptide synthetases in Aspergillus fumigatus is controlled by the availability of free iron. FEMS Microbiol. Lett. 248, 83-91. [PubMed: 15953695]

(27). Gründlinger M, Gsaller F, Schrettl M, Lindner H, and Haas H (2013) Aspergillus fumigatus SidJ mediates intracellular siderophore hydrolysis. Appl Environ. Microbiol. 79, 7534-6. [PubMed: 24038704]

(28). Altschul SF, Gish W, Miller W, Myers EW, and Lipman DJ (1990) Basic local alignment search tool. J. Mol. Biol. 215, 403-410. [PubMed: 2231712]

(29). Carver TJ, Rutherford KM, Berriman M, Rajandream M-A, Barrell BG, and Parkhill J (2005) ACT: the Artemis comparison tool. Bioinformatics 21, 3422-3423. [PubMed: 15976072]

(30). Medema MH, Takano E, and Breitling R (2013) Detecting Sequence Homology at the Gene Cluster Level with MultiGeneBlast. Mol. Biol. Evol 30, 1218-1223. [PubMed: 23412913]

(31). Moore GG, Mack BM, Beltz SB, and Puel O (2018) Genome sequence of an aflatoxigenic pathogen of Argentinian peanut, Aspergillus arachidicola. BMC Genomics 19, 189. [PubMed: 29523080]

(32). Steinchen W, Lackner G, Yasmin S, Schrettl M, Dahse H-M, Haas H, and Hoffmeister D (2013) Bimodular Peptide Synthetase SidE Produces Fumarylalanine in the Human Pathogen Aspergillus fumigatus. Appl. Environ. Microbiol. 79, 6670-6676. [PubMed: 23974138] 
(33). Wiemann P, Lechner BE, Baccile JA, Velk TA, Yin W-B, Bok JW, Pakala S, Losada L, Nierman WC, Schroeder FC, Haas H, and Keller NP (2014) Perturbations in small molecule synthesis uncovers an iron-responsive secondary metabolite network in Aspergillus fumigatus. Front. Microbiol. 5, 530. [PubMed: 25386169]

(34). Haas H, Eisendle M, and Turgeon BG (2008) Siderophores in Fungal Physiology and Virulence. Annu. Rev. Phytopathol. 46, 149-187. [PubMed: 18680426] 


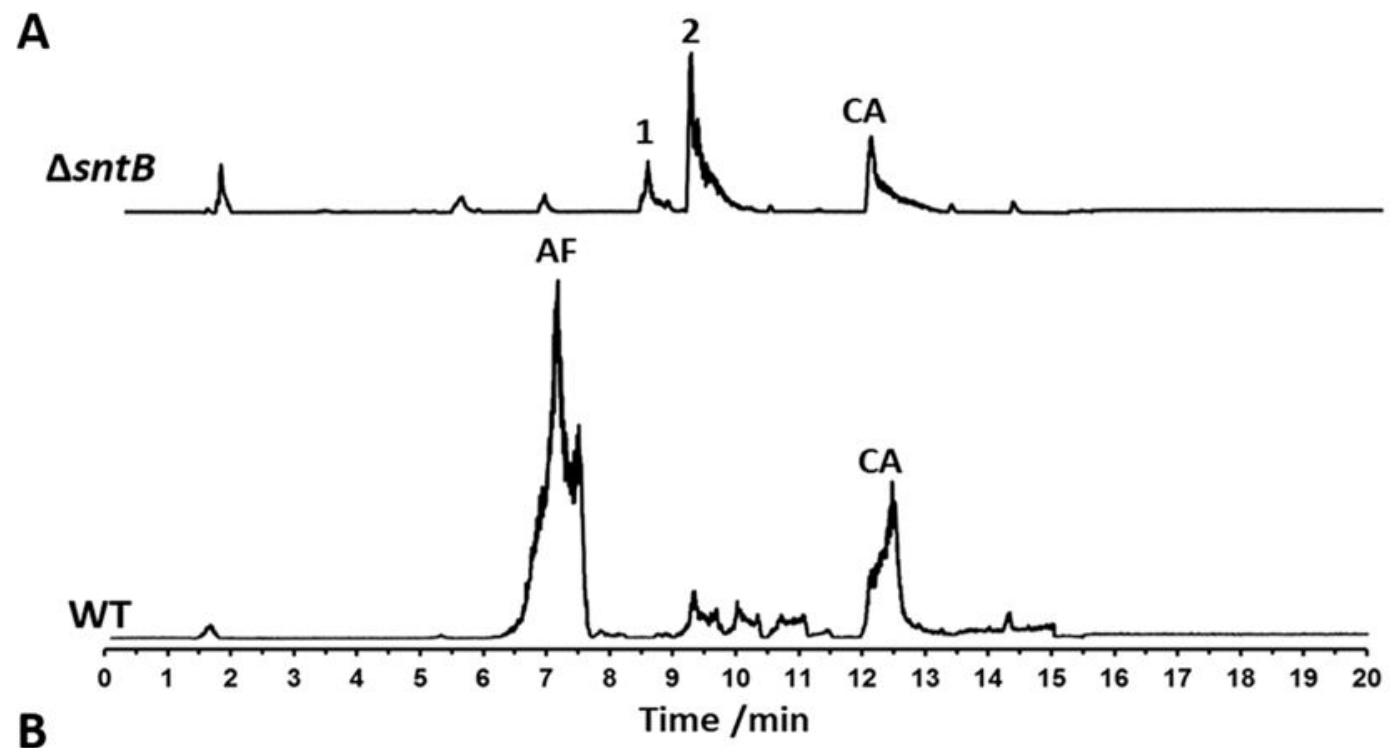

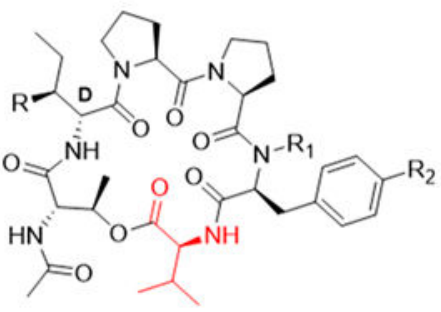

Aspergillicin $A$ 1: $R, R_{1}=M e ; R_{2}=O M e$ Aspergillicin B 3: R = H; $\mathrm{R}_{2}=\mathrm{Me} ; \mathrm{R}_{2}=\mathrm{OMe}$ Aspergillicin C 4: R, R $=M e ; R_{2}=H$ Aspergillicin D 5: R $=\mathrm{Me} ; \mathrm{R}_{1}=\mathrm{H} ; \mathrm{R}_{2}=\mathrm{H}$

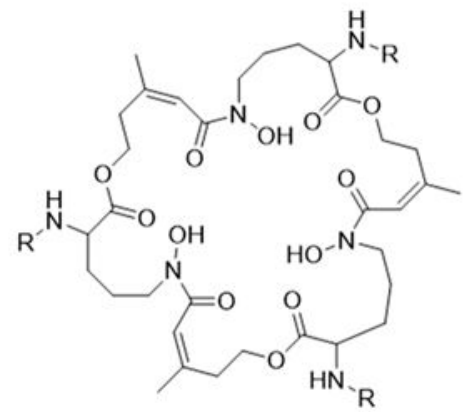

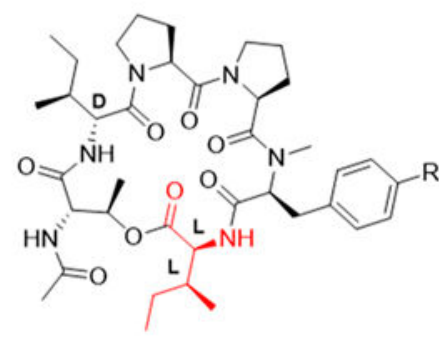

Aspergillicin $F$ 2: $R=O M e$ Aspergillicin G 11: $\mathrm{R}=\mathrm{H}$

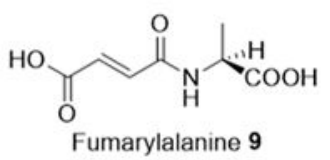

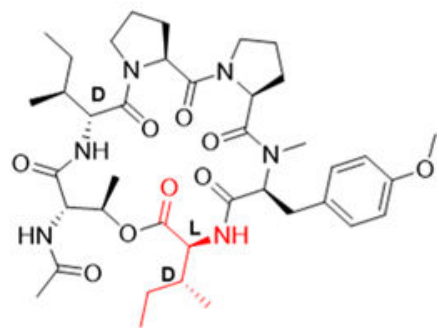

Aspergillicin E 6

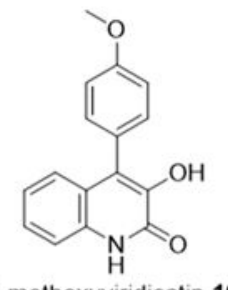

4'-methoxyviridicatin 10

Fusarinine $\mathrm{C}(\mathrm{FC}) 7, \mathrm{R}=\mathrm{H}$

$N, N, N "$-Triacetylfuasarinine C (TAFC) $8, \mathrm{R}=\mathrm{AC}$

Figure 1.

(A) UPLC-HRMS chromatograms (TIC, linked axis) of A.flavus wild-type (WT) and $\Delta s n t B$. Method 20-95\% $\mathrm{CH}_{3} \mathrm{CN} / \mathrm{H}_{2} \mathrm{O}$ gradient, $20 \mathrm{~min}$. $\mathrm{AF}=$ aflatoxin $\mathrm{B} 1 ; \mathrm{CA}=$ cyclopiazonic acid. (B) Structures of aspergillicins A-G, siderophores fusarinine and TAFC, fumarylalanine, and $4^{\prime}$-methoxyviridicatin. 
A)

B)
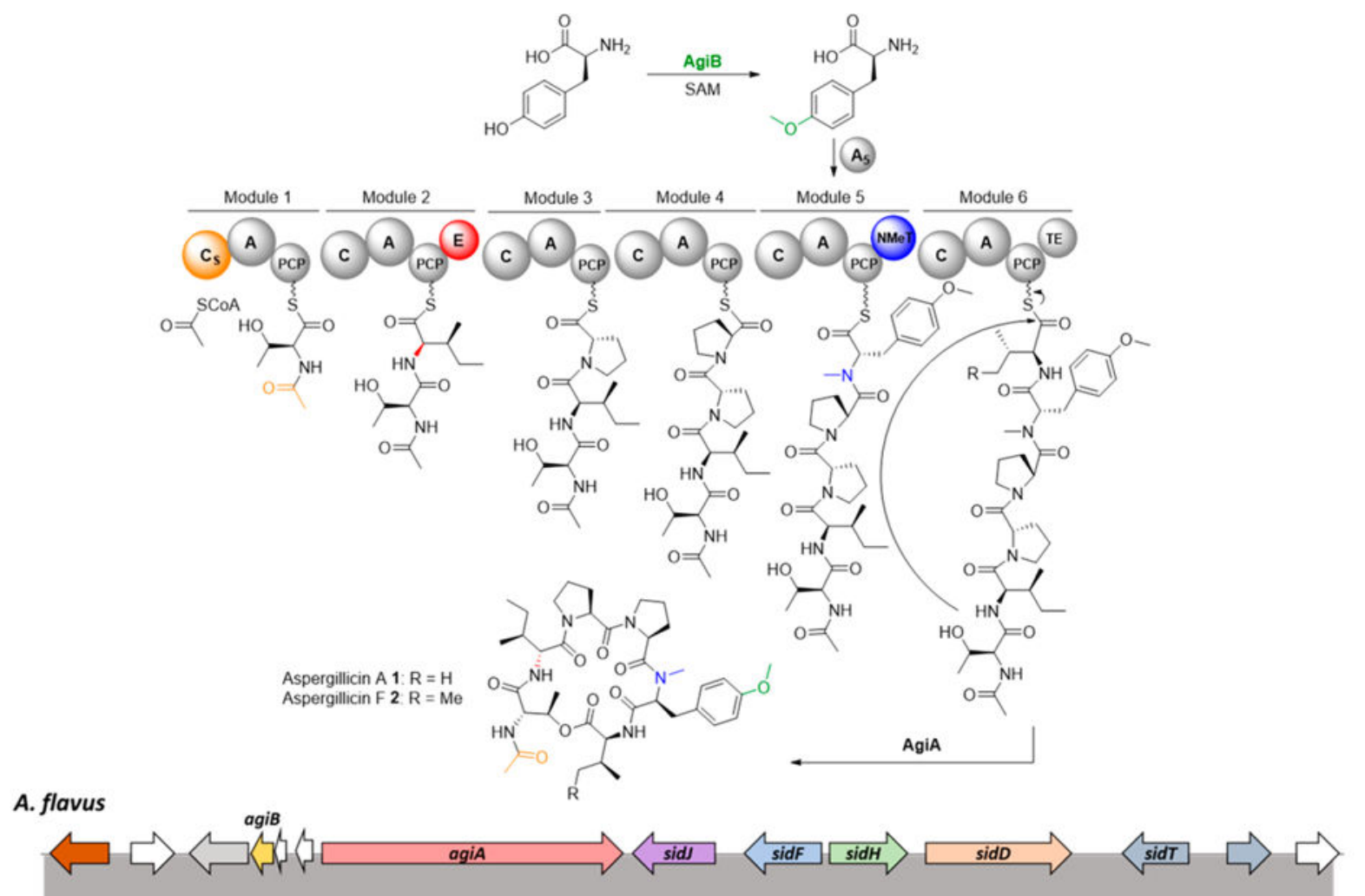

\section{A. oryzae}

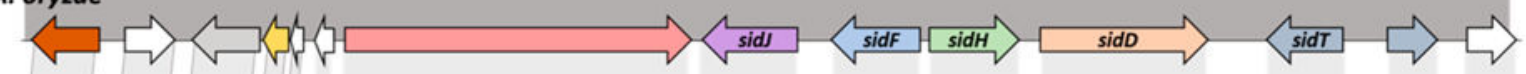

A. arachidicola

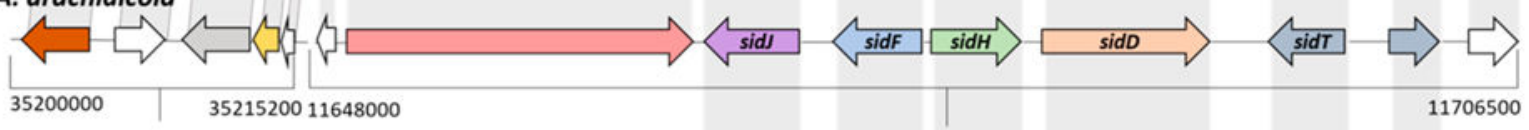

A. fumigatus
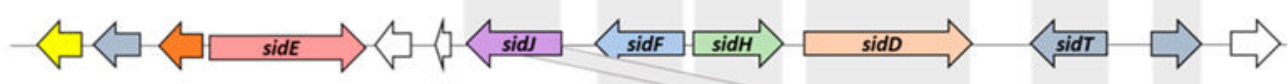

A. nidulans
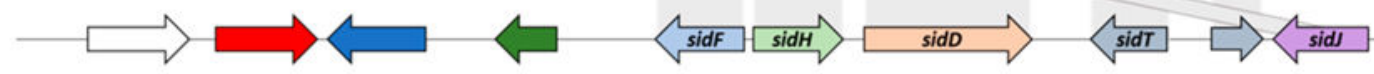

$\Rightarrow$ NRPS $\Rightarrow$ NRPS siderophore $\Rightarrow$ o-Methyl transferase

Siderophore esterase

Transporter $\Rightarrow$ Hypothetical

$\Rightarrow$ Siderophore $N$-Acetyl transferase $\Rightarrow$ Siderophore enoyl CoA hydratase $\Rightarrow$ Lipase $\Rightarrow$ Cytochrome P450

$\Rightarrow$ Tryptophan synthase $\Rightarrow$ V-type ATPase $\Rightarrow$ Chaperone Dnal domain $\Rightarrow$ Transcription factor $\Rightarrow$ Enoyl CoA reductase

Figure 2.

(A) Proposed biosynthesis of aspergillicin A and F. Different colors highlight specific domains and peptide modifications. Domains: $\mathrm{C}_{\mathrm{S}}$, starter condensation domain; A, adenylation; PCP, peptidyl carrier protein; C, condensation; E, epimerase; NMeT, $N$-methyl transferase; TE, thiolesterase. (B) Putative aspergillicin BGC and flanking genes. Synteny analysis identifies that siderophore genes are conserved across different Aspergillus species. In $A$. arachidicola, the BGC is in two different contigs, indicated by the two brackets. 


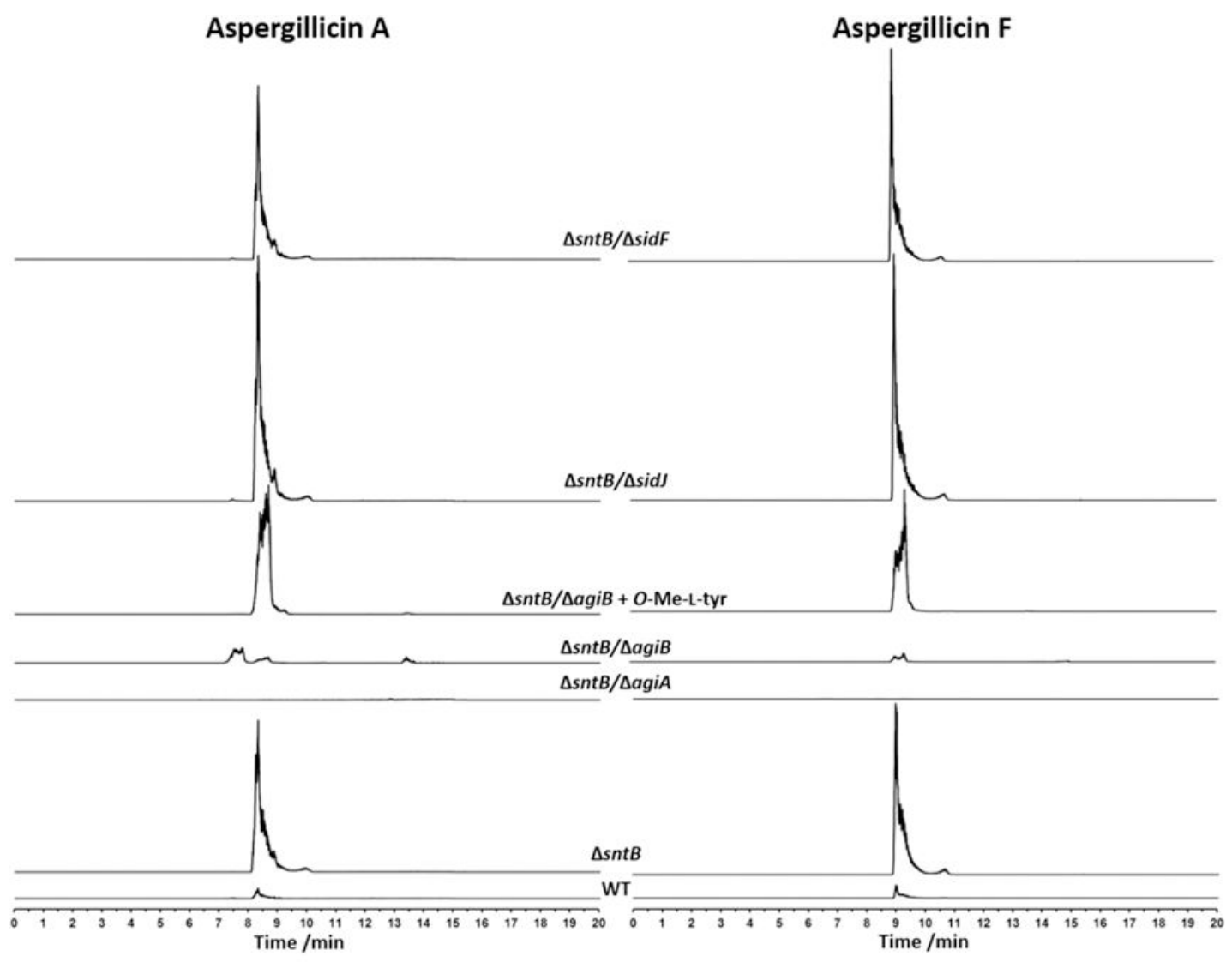

Aspergillicin B

Aspergillicin G

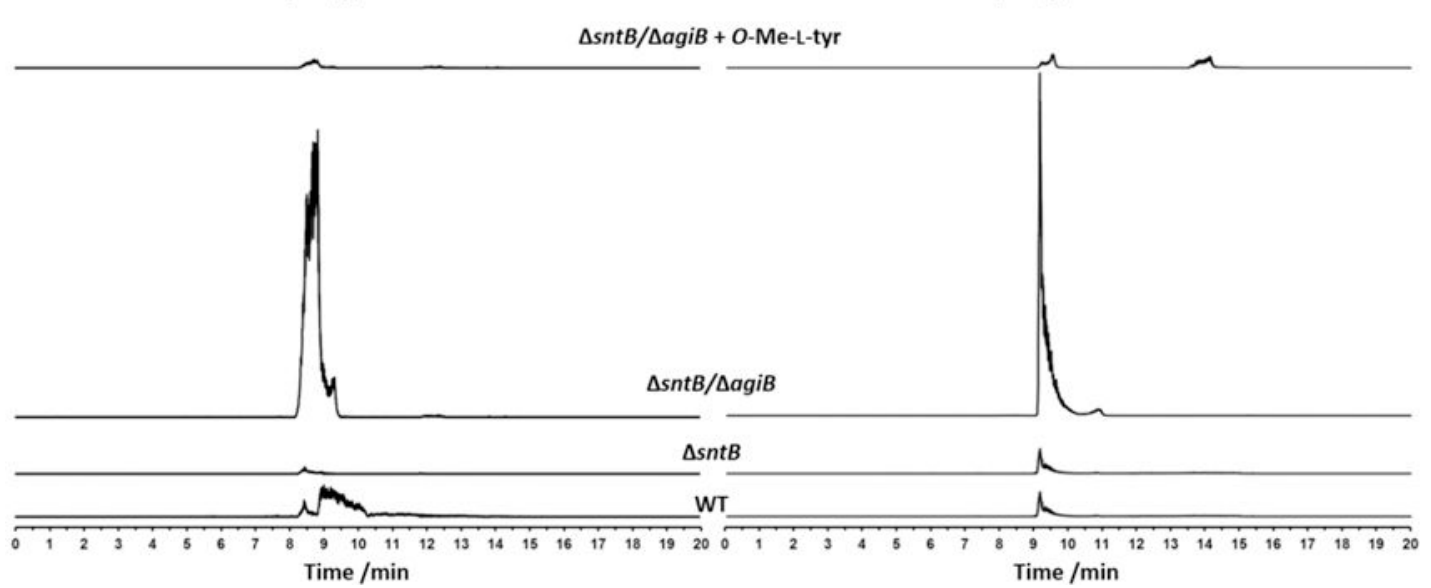

Figure 3.

UPLC-HRMS single ion chromatograms (linked axis), selecting the masses for aspergillicin A 1, aspergillicin F 2, aspergillicin C 4, and aspergillicin G 11. Method 20-95\% $\mathrm{CH}_{3} \mathrm{CN} / \mathrm{H}_{2} \mathrm{O}$ gradient, 20 min. 


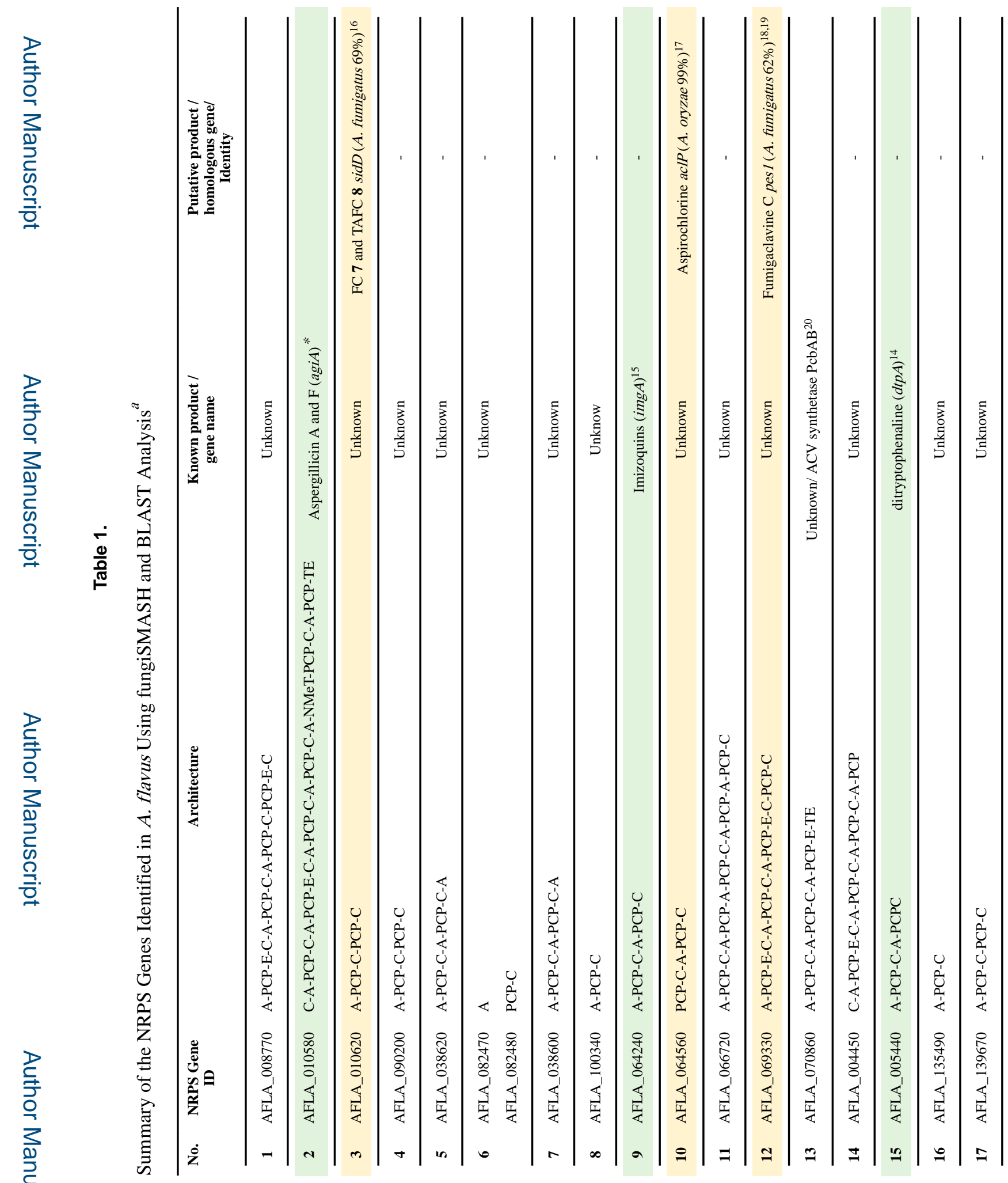




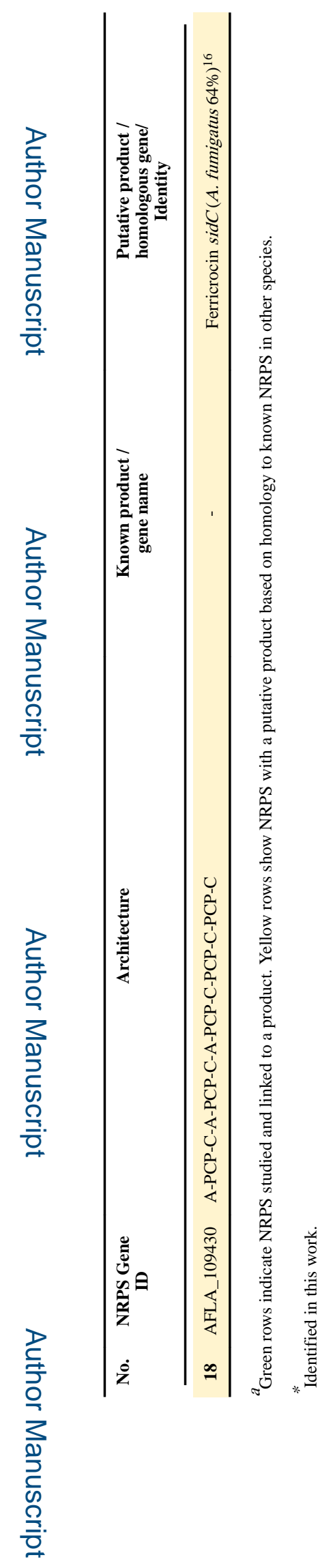

